\title{
Chemokine Signaling Controls Intracortical Migration and Final Distribution of GABAergic Interneurons
}

\author{
Guillermina López-Bendito, ${ }^{\star}$ Juan Antonio Sánchez-Alcañiz, ${ }^{\star}$ Ramón Pla, ${ }^{*}$ Víctor Borrell, Esther Picó, \\ Miguel Valdeolmillos, and Oscar Marín \\ Instituto de Neurociencias de Alicante, Consejo Superior de Investigaciones Científicas and Universidad Miguel Hernández, 03550 Sant Joan d’Alacant, \\ Spain
}

Functioning of the cerebral cortex requires the coordinated assembly of circuits involving glutamatergic projection neurons and GABAergic interneurons. Although much is known about the migration of interneurons from the subpallium to the cortex, our understanding of the mechanisms controlling their precise integration within the cortex is still limited. Here, we have investigated in detail the behavior of GABAergic interneurons as they first enter the developing cortex by using time-lapse videomicroscopy, slice culture, and in utero experimental manipulations and analysis of mouse mutants. We found that interneurons actively avoid the cortical plate for a period of $\sim 48 \mathrm{~h}$ after reaching the pallium; during this time, interneurons disperse tangentially through the marginal and subventricular zones. Perturbation of CXCL12/CXCR4 signaling causes premature cortical plate invasion by cortical interneurons and, in the long term, disrupts their laminar and regional distribution. These results suggest that regulation of cortical plate invasion by GABAergic interneurons is a key event in cortical development, because it directly influences the coordinated formation of appropriate glutamatergic and GABAergic neuronal assemblies.

Key words: cerebral cortex; interneuron; CXCL12; CXCR4; migration; layering; regional distribution; tangential dispersion

\section{Introduction}

In the mammalian cerebral cortex, probably the most complex of all neuronal assemblies, the coordinated activity of glutamatergic projection neurons and GABAergic interneurons underlies the emergence of fundamental physiological properties, such as the dynamic behavior of receptor fields or the modulation of cortical oscillations underlying various brain functions (McBain and Fisahn, 2001; Hensch, 2005; Somogyi and Klausberger, 2005). What is most remarkable about the cerebral cortex is that the neuronal populations sustaining the optimal excitatory-inhibitory balance follow different developmental programs. Thus, whereas glutamatergic neurons originate throughout the ventricular zone (VZ) of the pallium and migrate radially to establish the different layers of the cortex, GABAergic interneurons derive

Received 0ct. 12, 2007; revised Dec. 14, 2007; accepted Dec. 17, 2007.

This work was supported by Spanish Ministry of Education and Science (MEC) Grants BFU2005-04773/BMC and CONSOLIDER CSD2007-0003, by the Fundació "la Caixa," by the European Commission through STREP contract number 005139 (INTERDEVO), and by the European Young Investigator (EURYI) program (0.M.); and by Spanish MEC Grant BFU2005-02393 (M.V.). G.L.-B. was a "Ramón y Cajal" Investigator from the Consejo Superior de Investigaciones Científicas (CSIC). R.P. and J.A.S.-A. were supported by Formación de Personal Investigador and Formación de Profesorado Universitario fellowships from the Spanish MEC, respectively. V.B. is a "Ramón y Cajal" Investigator from the CSIC and a recipient of a Human Frontier Science Program Organization Career Development Award. O.M. is a European Molecular Biology Organization Young Investigator and an EURYI Awardee. We thank M. Bonete, T. Gil, and M. Pérez for excellent technical assistance; G. D'Arcangelo and V. Pachnis for plasmids and reagents; and A. Nagy $(G f p), G$. Szabó (Gad65 $5^{G f p}$ ), and D. R. Littmann and V. Ödemis ( $(x c r 4)$ for mouse strains. We are grateful to M. Maravall for help with statistical tools and analysis, to members of the Marín and Rico laboratories for stimulating discussions, and to $S$. J. Pleasure for communicating unpublished results.

${ }^{*}$ G.L.-B., J.A.S.-A., and R.P. contributed equally to this work.

Correspondence should be addressed to Dr. Oscar Marín at the above address. E-mail: o.marin@umh.es.

D01:10.1523/JNEUROSCI.4651-07.2008

Copyright $\odot 2008$ Society for Neuroscience $\quad$ 0270-6474/08/281613-12\$15.00/0 from the $\mathrm{VZ}$ of the subpallium and reach the developing cortex through a long tangential migration (Corbin et al., 2001; Marín and Rubenstein, 2001).

The guidance of GABAergic interneurons from the subpallium to the developing cortex relies on multiple factors, many of which have been identified (Marín and Rubenstein, 2003; Métin et al., 2006). For example, brain-derived neurotrophic factor, glial cell line-derived neurotrophic factor, and hepatocyte growth factor have been shown to promote the migration of cortical GABAergic interneurons as they migrate from the medial ganglionic eminence (MGE) (Powell et al., 2001; Polleux et al., 2002; Pozas and Ibañez, 2005). In addition, class III semaphorins and neuregulin-1 act in concert as chemorepellents and a chemoattractant, respectively, to guide migrating GABAergic interneurons from the MGE toward the cortex (Marín et al., 2001; Flames et al., 2004).

After entering the cortex, interneurons disperse tangentially via highly stereotyped routes in the marginal zone (MZ), subplate, and lower intermediate zone/subventricular zone (IZ/SVZ) (Lavdas et al., 1999). Eventually, interneurons switch from tangential to radial migration to adopt their final laminar position in the cerebral cortex (Polleux et al., 2002; Ang et al., 2003; Tanaka et al., 2003). Many GABAergic interneurons and projection neurons born approximately at the same time end up occupying the same cortical layer (Miller, 1985; Fairén et al., 1986; Nery et al., 2002; Valcanis and Tan, 2003), suggesting that the mechanisms controlling the final distribution of GABAergic interneurons are coordinated with those governing the allocation of projection neurons. Our understanding of the cellular and molecular events underlying the last steps in the migration of interneurons within 
the cortex is still very fragmentary. Several hypotheses have been proposed to explain the coordinated assembly of GABAergic interneurons and projection neurons, but the underlying mechanisms are unknown (Nadarajah and Parnavelas, 2002; Kriegstein and Noctor, 2004; Pla et al., 2006). For example, GABAergic interneurons do not seem to rely on the Reelin/Dab1 signaling pathway to adopt their final laminar position (Pla et al., 2006), which suggests that additional molecules may exist that govern the last steps in the migration of GABAergic interneurons within the developing cortex.

Recently, it has been reported that CXCL12, a member of the CXC subfamily of chemokines [also known as SDF-1 (stromal cell-derived factor-1)], is expressed in the meninges and in the SVZ of the developing cortex in a pattern that is consistent with a role for this molecule in the intracortical guidance of GABAergic interneurons (Stumm et al., 2003; Tiveron et al., 2006; Stumm et al., 2007). However, to what extent this signaling system is directly required for the migration of interneurons within the cortex and how this process may influence their final distribution in the cortex remains to be elucidated.

\section{Materials and Methods}

Mouse lines. Wild-type and green fluorescent protein (GFP)-expressing transgenic mice (Hadjantonakis et al., 1998) were maintained in a CD1 background. Mice carrying a loss-of-function allele for Cxcr4 (Zou et al., 1998) and Gad65 Gfp (López-Bendito et al., 2004) transgenic mice were maintained in a $\mathrm{C} 57 \mathrm{~b} / 6$ background. Animals were kept at the Instituto de Neurociencias de Alicante under Spanish and European Union regulations.

Isochronic and heterochronic microtransplants. Brain slices were obtained from wild-type or Gfp transgenic embryos as described previously (Anderson et al., 1997). Small embryonic day 13.5 (E13.5) MGE explants from donor slices (obtained from GFP mice) were transplanted into the VZ of the neocortex of E13.5, E15.5, or E17.5 wild-type slices, which were subsequently cultured for $48 \mathrm{~h}$. Similar microtransplantation experiments were performed using the MGE of wild-type and $\mathrm{Cxcr}^{-/-}$embryos; in this case, donor pregnant females were injected with bromodeoxyuridine (BrdU; $40 \mathrm{mg} / \mathrm{kg}$ ) $12 \mathrm{~h}$ before dissection to identify the transplanted cells.

Time-lapse videomicroscopy. A Gfp expression vector was focally electroporated in the MGE of E13.5 wild-type or $\mathrm{Cxcr}^{-/-}$embryos as described previously (Flames et al., 2004). After $24-36 \mathrm{~h}$ in culture, slices were transferred to the stage of either an upright Leica (Nussloch, Germany) DMLFSA microscope coupled to a confocal spectral scanning head (Leica TCS SL) and viewed through $10-60 \times$ water-immersion objectives or to an inverted Leica DMIRE2 microscope coupled to a confocal spectral scanning head (Leica TCS SP) and viewed through $20 \times$ dry objectives. Slices were superfused continuously with warmed $\left(32^{\circ} \mathrm{C}\right)$ artificial CSF at a rate of $1 \mathrm{ml} / \mathrm{min}$ or incubated in a Leica chamber at $37^{\circ} \mathrm{C}$ and $5 \% \mathrm{CO}_{2}$. GFP was excited at $488 \mathrm{~nm}$, and fluorescence was measured at $505-545 \mathrm{~nm}$. XYZ stacks of images were acquired in the sequential scanning mode to minimize channel cross talk.

Coculture experiments. E13.5 MGE explants were confronted with COS cell aggregates in collagen matrix and incubated $36 \mathrm{~h}$ at $37^{\circ} \mathrm{C}$ in Neurobasal medium (Invitrogen, San Diego, CA). Collagen (Rat Tail Collagen I; BD Biosciences, Franklin Lake, NJ) was diluted 1:3 with Neurobasal, and $7 \% \mathrm{NaHCO}_{3}$ was added to jellify the matrix. COS7 cell aggregates expressing $d s R e d$ alone, or $d s R e d$ and Cxcl12, were prepared by diluting transfected cells with Matrigel in a 1:1 proportion, as described previously (Borrell and Marín, 2006). For CXCR4 receptor-blocking experiments, AMD3100 solution (30 $\mu \mathrm{m}$; Sigma, St. Louis, MO) was added to the medium at the beginning of the culture period and $24 \mathrm{~h}$ later; control cultures received identical volumes of vehicle solution (PBS).

In utero drug administration. In vivo blocking of CXCR4 function was performed as described previously (Borrell and Marín, 2006). Briefly, timed-pregnant CD1 females were deeply anesthetized, and the abdominal cavity was cut open. Embryos were exposed in the uterus, and $1 \mathrm{ml}$ of
AMD3100 or vehicle solution (PBS) was injected into the telencephalic lateral ventricle. The uterine horns were placed back in the abdominal cavity, which was then suture closed, and the female was allowed to recover.

In utero transplantation. In utero ultrasound-guided transplantation of MGE-derived cells was performed as described previously (Pla et al., 2006). For each experiment, the MGEs from three to four E15.5 GFPexpressing mice and one to two E15.5 $\mathrm{CxCr} 4^{-/-}$embryos were dissected under a stereomicroscope. Explants were washed in $0.5 \mathrm{ml}$ of L-15 medium (Invitrogen) containing DNase I $(100 \mu \mathrm{g} / \mathrm{ml})$, and cells were mechanically dissociated by repeated pipetting. Dissociated cells were then mixed together and pelleted by centrifugation ( $5 \mathrm{~min}, 1000 \mathrm{rpm})$, resuspended in $6 \mu \mathrm{l}$ of L-15 medium with DNase I, and kept on ice until injection. All donor pregnant females were given injections of BrdU $12 \mathrm{~h}$ before dissection. Cxcr $4^{-/-}$embryos were genotyped as described previously (Borrell and Marín, 2006). High-density cell suspensions $(25,000$ cells/ $\mu \mathrm{l}$ ) were front-loaded into beveled glass micropipettes $(50 \mu \mathrm{m} \mathrm{di}$ ameter) prefilled with mineral oil and mounted in a pressure microinjector (VisualSonics, Toronto, Ontario, Canada). Recipient pregnant females at E15.5 were anesthetized with sodium pentobarbital $(0.625$ $\mathrm{mg} / 10 \mathrm{~g}$, i.p.), and their uterine horns were exposed and mounted under an ultrasound microscope (VisualSonics, Toronto, Ontario, Canada). The tip of the micropipette was inserted into the MGE under real-time ultrasound guidance, and 30-50 $\mathrm{nl}$ of cell suspension was injected. Consistent with previous observations (Wichterle et al., 2001; Butt et al., 2005), the large majority of MGE-derived cells found in the cortex of postnatal host mice differentiated into neurons (data not shown).

In situ hybridization and immunohistochemistry. Twenty micrometer frozen brain sections were hybridized with digoxigenin-labeled probes as described previously (Flames et al., 2004). The following cDNA probes were used: Cxcl12 (clone number 3483088; Invitrogen), Cxcr4 (clone number 4457694; Invitrogen), Reln (D'Arcangelo et al., 1995), and Lhx6 (Grigoriou et al., 1998). For immunohistochemistry of frozen brain sections or slice cultures, tissue was fixed for $4 \mathrm{~h}$ in $4 \%$ paraformaldehyde (PFA), washed in PBS, and incubated with primary antibodies overnight, followed by appropriate secondary antibodies. For immunohistochemistry in MGE explants, cultures were fixed for $1 \mathrm{~h}$ in 4\% PFA, incubated in $2 \%$ BSA and $0.5 \%$ Triton X-100 in phosphate buffer for $6 \mathrm{~h}$ at room temperature, and subsequently incubated with primary antibodies for $36 \mathrm{~h}$ at $4^{\circ} \mathrm{C}$. After washing, appropriate fluorescent secondary antibodies were used. For immunohistochemistry on postnatal animals, mice were anesthetized with an overdose of sodium pentobarbital and perfused transcardially with $4 \%$ PFA. Postnatal brains were removed, fixed for $3 \mathrm{~h}$ at $4^{\circ} \mathrm{C}$, and cryoprotected in $30 \%$ sucrose in PBS. Brains were then cut frozen transversally on a sliding microtome at $40 \mu \mathrm{m}$ and incubated with primary antibodies for $36 \mathrm{~h}$ at $4^{\circ} \mathrm{C}$, followed by appropriate secondary antibodies. For BrdU double staining, sections were first processed for Lhx6 or GFP immunohistochemistry, fixed in 4\% PFA for $50 \mathrm{~min}$, and processed for BrdU staining. Fluorescent stainings were counterstained with Hoechst (Sigma) to assist the delineation of cortical compartments. For light microscopy preparations, adjacent sections were stained with Nissl to delineate the layers of the embryonic cortex. Primary antibodies used were rat anti-BrdU (1:100; Accurate, Westbury, NY), chicken antiGFP (1:1000; Aves), and rabbit anti-Lhx6 (1:2000; kindly provided by V. Pachnis, National Institute for Medical Research, London, UK). Secondary antibodies used were Alexa488 goat anti-chicken, Alexa546 goat antirat, and Alexa546 goat anti-rabbit (Invitrogen), all diluted 1:200.

Quantification. For the quantification of COS cell confrontation assays, each MGE explant was subdivided in four quadrants oriented to the COS cell aggregates, and the distance migrated by the 20 furthest cells in the proximal and distal quadrants was quantified.

Microtransplantation experiments were quantified using a $1 \mathrm{~cm}$ measuring reticular adapted to a $20 \times$ objective in a Leica fluorescent microscope. Cells were classified as located inside or outside the cortical plate (CP) using the bis-benzamide staining of the slice. The area was measured using the open domain Image J analysis software (W. S. Rasband, National Institutes of Health, Bethesda, MD; http://rsb.info.nih.gov/ij/, 1997-2006).

For the quantification of Lhx6 or Lhx6/BrdU + and BrdU + cells in 


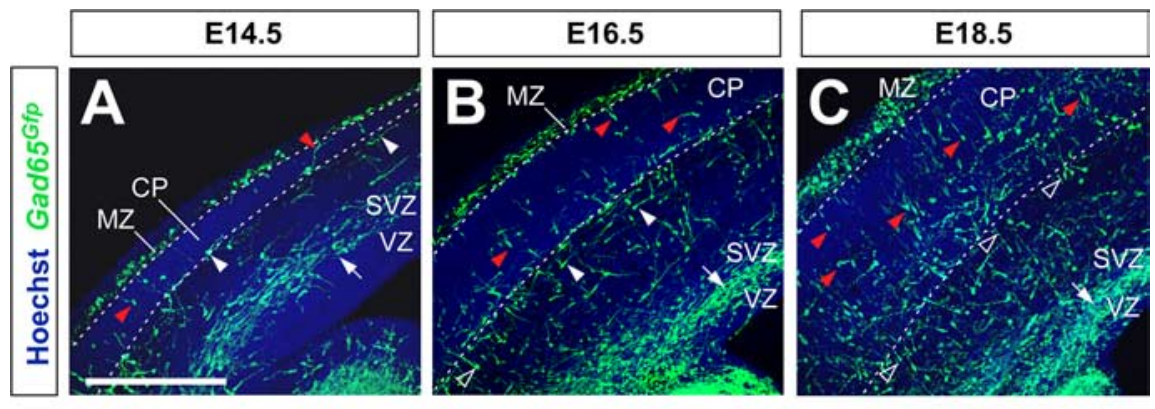

D
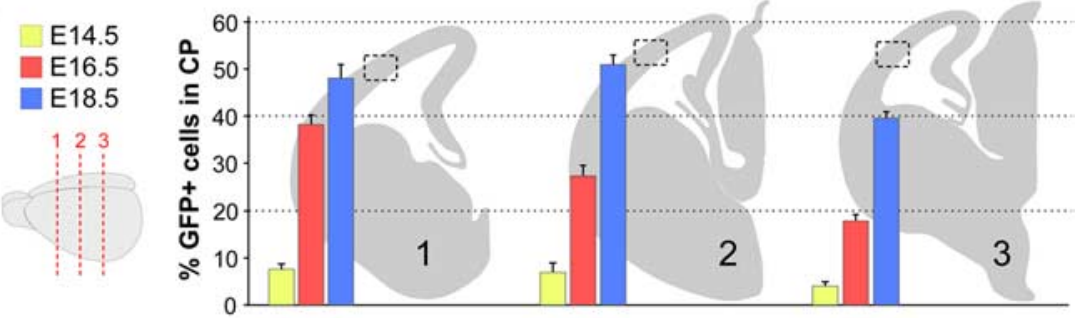

$\mathbf{E}$

E16.5

E14.5

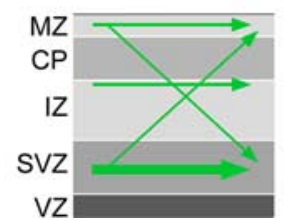

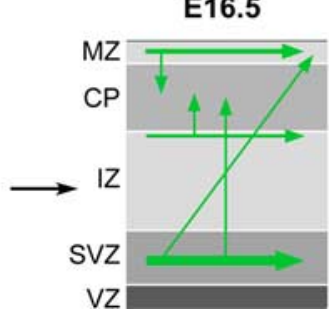

$\mathrm{VZ}$

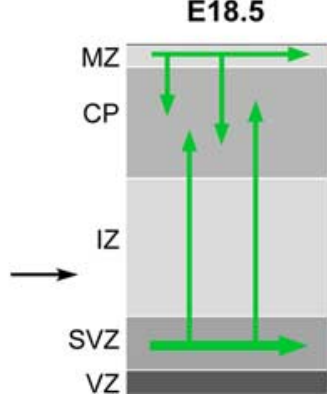

Figure 1. Dynamics of CP invasion by GABAergic neurons. $A-C$, Distribution of $G a d 65^{G f p}$ interneurons in the developing cortex of E14.5, E16.5, and E18.5 mouse embryos. Red and open arrowheads point to cells in the CP or those entering this zone, respectively, whereas white arrowheads and arrows point to cells tangentially migrating through the subplate and SVZ, respectively. $\boldsymbol{D}$, Quantification of the relative percentage of GFP-expressing cells found in the (P at different developmental stages in rostral (1), intermediate (2), and caudal (3) telencephalic levels. Histograms show average + SEM. E14.5: 7.6 \pm 1.19 (1), $6.9 \pm$ $0.82(2)$, and 4.2 $\pm 0.61(3) ; E 16.5: 38.4 \pm 3.19(1), 27.5 \pm 3.98(2)$, and 18.1 $\pm 2.02(3) ; E 18.5: 48.4 \pm 2.83(1), 52.8 \pm 3.41$ (2), and $40.5 \pm 1.59$ (3). $\boldsymbol{E}$, Schemas summarizing the main migratory routes used by Gad65 $5^{6 f p}$ interneurons at different developmental stages. Scale bar, $200 \mu \mathrm{m}$.

E14.5 and E16.5 embryos, respectively, confocal images coupled using Canvas software were analyzed. Cells were counted from a $375-\mu \mathrm{m}$-wide profile of the dorsal cortex at intermediate rostrocaudal levels in at least three different animals. The cortex was analyzed with a grid of 10 equal horizontal bins. Bin 1 roughly corresponds to the MZ, and bin 10 corresponds to the VZ. For the quantification of the laminar distribution of wild-type (GFP/BrdU+) and Cxcr4 ${ }^{-1-}(\mathrm{BrdU}+)$ transplanted neurons in postnatal day 14 (P14) animals, all cells present in the cortex were plotted and assigned to different layers of the cortex using photomontages with fluorescence nuclear staining as a cytoarchitectonic reference. To examine differences across populations, data were statistically analyzed using $\chi^{2}$ tests. For those distributions of cells in which statistical differences were found for the entire population, each category (layers or bins, depending on the experiment) was then independently analyzed using two-by-two contingency tables to assign statistical differences to specific categories.

For the analysis of the tangential dispersion of wild-type and $C x \mathrm{Cr}^{-1-}$ transplanted neurons in P14 animals, all cells found in the cerebral cortex were mapped, and their mediolateral (ML) and anteroposterior (AP) positions along the cerebral cortex were measured with respect to the midline and the rostral end of the cerebral cortex, respectively. The center-mass point for each population of cells was then calculated, defined as the intersection between a line splitting the population of cells in two halves in the AP axis and a line splitting the population of cells in two halves in the ML axis. Then we measured the radial distance from each
E18.5

individual cell to the center-mass point. The entire population of transplanted cells was then ordered according to their absolute distances to the population center-mass point and divided into five groups (i.e., the $20 \%$ of cells closest to the center-mass point were classified as belonging to the $20 \%$ group; the $40 \%$ of cells closest to the center mass point as belonging to the $40 \%$ group, etc.). Next, the original AP and ML coordinates for each cell were used to plot all individual cells on a two-dimensional space representing the flattened cerebral cortex, using a custom-made Matlab-based program. Finally, the absolute area occupied by each group of cells within this two-dimensional space was measured. To examine differences across the rostrocaudal and ML distribution of each animal, data were statistically analyzed using the Kolmogorov-Smirnov test.

For the quantification of the migratory speed of control and $\mathrm{CxCr} 4^{-1-}$ neurons, the distance migrated by individual cells in slice cultures was calculated from time-lapse movies by tracking the position of the cell soma using the XYZ Points Tool from the ImageJ software. Speed was calculated as the fraction between the total distance migrated and the time elapsed between the first and last frame measured.

\section{Results \\ $\mathrm{CP}$ invasion by GABAergic neurons is temporally regulated}

Previous studies have shown that the intracortical migration of GABAergic interneurons is a highly dynamic process, in which interneurons adopt different modes of migration as they disperse throughout the developing cortex (Nadarajah et al., 2002; Tanaka et al., 2003, 2006; López-Bendito et al., 2004). However, little is known about the mechanisms used by GABAergic interneurons to colonize the entire cortical wall and eventually allocate into specific layers of the developing cortex. To study this process, we took advantage of a transgenic mouse strain in which GFP is specifically expressed in GABAergic neurons (LópezBendito et al., 2004). Analysis of the cortex in Gad65 ${ }^{G f p}$ embryos at different stages of development reveals important differences in the intracortical distribution of GABAergic neurons (Fig. 1). At E14.5, most GABAergic interneurons were found in two main streams, one coursing through the $\mathrm{MZ}$ and another one, more prominent, in the lower IZ/SVZ throughout the entire cerebral cortex (Fig. $1 A, E$ ). In contrast, very few cells were observed in the $\mathrm{CP}$ at rostral, medial, or caudal levels of the cortex at this stage (Fig. 1A,D,E). At E16.5, most interneurons were still found in the $\mathrm{MZ}$ and SVZ, although the number of GABAergic neurons present in the CP substantially increased compared with those found at E14.5 (Fig. $1 B, D, E$ ). By E18.5, the number of interneurons found in the CP increased dramatically compared with earlier stages, accounting for nearly $40 \%$ of GFP-expressing cells in the cortex. Interestingly, the few neurons found in the CP at E14.5 appeared to follow oblique trajectories, whereas most cells in the $\mathrm{CP}$ at later stages were found to be radially oriented (Fig. $1 A-C$ ). These results suggest that the process of CP invasion by GABAergic interneurons is temporally regulated (Fig. $1 E$ ). 


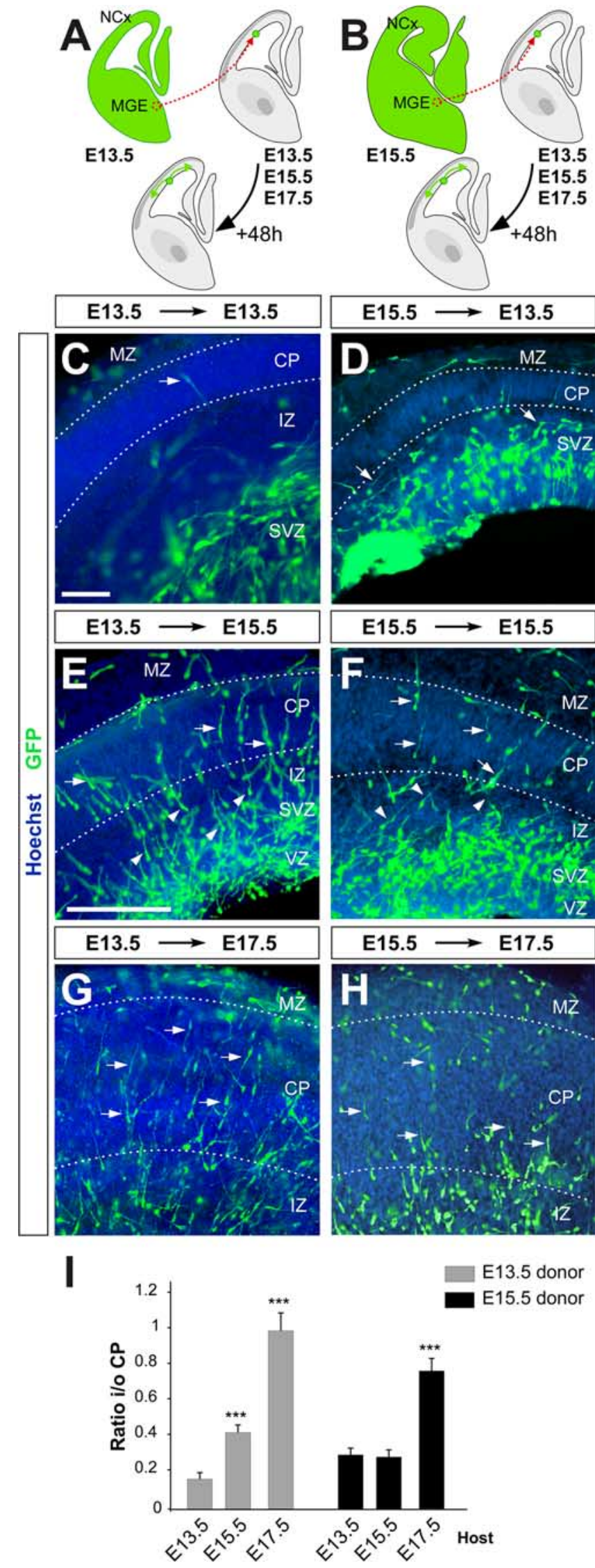

Figure 2. Intracortical cues govern the invasion of the CP by GABAergic neurons. $A, B, S$ Schematic diagrams of the experimental design in microtransplantation assays, in which E13.5 $(\boldsymbol{C}, \boldsymbol{E}$, G) or E15.5 $(\boldsymbol{D}, \boldsymbol{F}, \boldsymbol{H})$ MGE explants were transplanted to the VZ of the cortex in slice cultures at different developmental stages. NCX, Neocortex. $C, E, G$, Immunohistochemistry for GFP and
Intracortical dispersion of GABAergic neurons is controlled by cortical cues

Our previous observations reveal that GABAergic neurons disperse tangentially through the cortex at early embryonic stages, only invading the $\mathrm{CP}$ at later stages. This behavior may reflect that cortical interneurons are unable to enter the $\mathrm{CP}$ until they reach a certain stage of maturation. To test this hypothesis, we transplanted portions of the MGE from GFP-expressing transgenic embryos into the cortical VZ of host slices obtained from wildtype embryos at different developmental stages (Fig. 2A,B). Analysis of isochronic transplants of E13.5 MGE ${ }^{\text {GFP }}$ into E13.5 host slices revealed that most MGE-derived cells disperse tangentially throughout the cortex, and only a small fraction of the migrating neurons were located in the $\mathrm{CP}(3.2 \%$ neurons in $\mathrm{CP}$; $n=14$ ) (Fig. 2C,I). In contrast, heterochronic transplantation of E13.5 $\mathrm{MGE}^{\mathrm{GFP}}$ into the cortical VZ of E15.5 host slices revealed an increasing number of migrating neurons present in the developing CP (14.2\% neurons in CP; $n=32$ ) (Fig. $2 E, I)$, and even more so when transplanted in E17.5 host slices (29.8\% neurons in CP; $n=11$ ) (Fig. 2G,I). In agreement with our previous observations in Gad65 ${ }^{G f p}$ mouse embryos, we found that GFP + neurons located in the CP of E15.5 and E17.5 host slices typically displayed a radially oriented morphology. Finally, when the same E13.5 explant was simultaneously confronted with E13.5 and E15.5 host cortical slices, MGE ${ }^{\text {GFP }}$ cells migrating into the E15.5 slice invaded the $\mathrm{CP}$, whereas those migrating into the E13.5 slice did not $(n=12)$ (supplemental Fig. S1, available at www. jneurosci.org as supplemental material).

The previous results indicated that early cortical GABAergic neurons (E13.5) only invade the CP after E15.5, suggesting that a change in the cortical environment around this stage may coordinate the entry of migrating interneurons into the $\mathrm{CP}$. Because interneurons are born through a relatively long period of time (Hevner et al., 2004), we next tested the ability of late-born interneurons (E15.5) to invade the $\mathrm{CP}$ at different stages. For this, we transplanted portions of the MGE from E15.5 GFP-expressing transgenic embryos into the cortical VZ of host slices obtained from wild-type embryos at different developmental stages (Fig. $2 B$ ). As expected from the previous experiments, analysis of heterochronic transplants of E15.5 MGE ${ }^{\mathrm{GFP}}$ into E13.5 host slices revealed that only a small fraction of MGE-derived cells invades the CP (6.1\% neurons in CP; $n=28)$ (Fig. 2D, I; supplemental movie $\mathrm{S} 1$, available at www.jneurosci.org as supplemental material). Somehow surprisingly, isochronic transplantation of E15.5 MGE $^{\text {GFP }}$ into E15.5 host slices also resulted in the accumulation of very few transplanted neurons in the developing CP $(9.1 \%$ neurons in CP; $n=44$ ) (Fig. $2 F, I$ ). In contrast, heterochronic transplantation of E15.5 MGE ${ }^{\mathrm{GFP}}$ into the cortical VZ of E17.5 host slices revealed many migrating neurons present in the developing CP (24.6\% neurons in CP; $n=22$ ) (Fig. $2 H, I)$. These results suggest that $\mathrm{MGE}$-derived neurons only tend to invade the $\mathrm{CP}$ when confronted to relatively older tissue, indicating that the invasion of the $\mathrm{CP}$ is temporally delayed for each cohort of

Hoechst staining in E13.5 slice microtransplantation assays after $48 \mathrm{~h}$ in culture. $\boldsymbol{D}, \boldsymbol{F}, \boldsymbol{H}, \mathrm{Immu}$ nohistochemistry for GFP and Hoechst staining in E15.5 slice microtransplantation assays after $48 \mathrm{~h}$ in culture. The dashed lines delineate the extent of the CP. Arrows and arrowheads point to cells inside or outside the $C P$, respectively. $I$, Quantification of the ratio of cell density inside/ outside (i/0) the (P in microtransplants assays. Histograms show average + SEM. E13.5-E13.5, $0.16 \pm 0.03 ; \mathrm{E} 13.5-\mathrm{E} 15.5,0.42 \pm 0.04 ; \mathrm{E} 13.5-\mathrm{E} 17.5,0.98 \pm 0.1 ; \mathrm{E} 15.5-\mathrm{E} 13.5,0.32 \pm 0.03$; $\mathrm{E} 15.5-\mathrm{E} 15.5,0.29 \pm 0.03 ; \mathrm{E} 15.5-\mathrm{E} 17.5,0.80 \pm 0.08$. $p$ values refer to isochronic transplants in each case. ${ }^{* * *} p<0.001, t$ test. Scale bars: $\boldsymbol{C}, \boldsymbol{D}, 100 \mu \mathrm{m} ; \boldsymbol{E}-\boldsymbol{H}, 200 \mu \mathrm{m}$. 


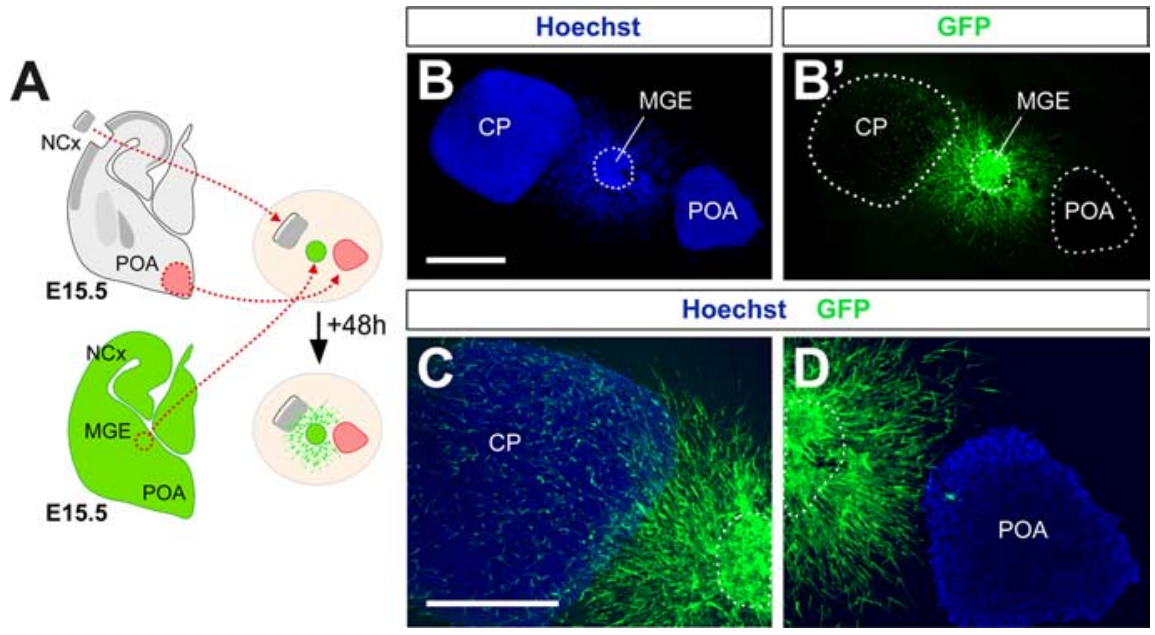

Figure 3. The CP is a permissive territory for MGE-derived cells. $\boldsymbol{A}$, Schematic diagram of the experimental design. NCx, Neocortex. $\boldsymbol{B}$, $\boldsymbol{B}^{\prime}$, Nuclear staining $(\boldsymbol{B})$ and GFP immunohistochemistry $\left(\boldsymbol{B}^{\prime}\right)$ in a coculture assay in which an explant of the MGE from a GFP-expressing mouse embryo was confronted to explants from the CPand POA in a Matrigel three-dimensional matrix for 36 h. $C, D$, High-magnification images showing GFP-expressing cells can invade the CP (C) but not the POA (D). Scale bars, $500 \mu \mathrm{m}$.

GABAergic interneurons. Altogether, these observations suggest that each cohort of newborn interneurons spend a similar period of time migrating through the cortex $(\sim 48 \mathrm{~h})$ before entering the developing CP.

The CP is a permissive territory for interneuron migration One plausible hypothesis to explain the behavior of migrating interneurons as they first enter the developing cortex is that the $\mathrm{CP}$ contains a repulsive or nonpermissive activity. Tangentially migrating interneurons would thereby avoid entering this cortical compartment and instead will continue their migration through the entire cortex. To test this idea, we performed coculture experiments in a three-dimensional matrix, in which we confronted E15.5 MGE ${ }^{\text {GFP }}$ explants to isolated CP explants dissected out from isochronic wild-type slices (Fig. 3A). As a control of the response of migrating interneurons to a nonpermissive territory, MGE ${ }^{\mathrm{GFP}}$ explants were also confronted to small portions of the anterior preoptic area (POA) (Fig. 3A), a region that has been shown to contain a nonpermissive activity for these neurons (Marín et al., 2003; Wichterle et al., 2003). Analysis of these coculture experiments revealed that MGE-derived cells are able to invade the isolated CP ( $>200$ cells in 19 of 25 explants) (Fig. $3 B, C$ ) but do not enter the POA explants ( $<10$ cells in 24 of 25 explants) (Fig. $3 B, B^{\prime}, D$ ). This result was also consistently observed when $C P$ and MGE explants were cocultured alone, without the POA ( $>200$ cells in 20 of 25 explants; data not shown). Thus, the CP does not contain a nonpermissive activity for MGEderived interneurons; instead, it seems that, if isolated from surrounding territories, the $\mathrm{CP}$ constitutes a permissive territory for the migration of cortical interneurons. Consistent with this notion, analysis of the migration of interneurons in acute E14.5 Gad65 ${ }^{G f P}$ slice cultures by time-lapse videomicroscopy revealed that these cells can move through the $\mathrm{CP}$ when changing from the $\mathrm{MZ}$ to the SVZ and vice versa (supplemental movie S2, available at www.jneurosci.org as supplemental material).

\section{Cxcl12 is expressed in the routes of tangential dispersion of interneurons}

Because tangentially migrating interneurons actively avoid the $\mathrm{CP}$ as they first enter the developing cortex, and the CP does not contain any repulsive activity for these neurons, a different mechanism should mediate the highly stereotyped dispersion of interneurons throughout the embryonic cortex. One possibility is that the routes of migration for cortical interneurons (i.e., the $\mathrm{MZ}$ and the SVZ) contain a more permissive or attractive activity than the $\mathrm{CP}$, thus contributing to maintain these cells away from the CP. Consistent with this possibility, the chemokine Cxcl12 is expressed in the MZ and SVZ of the embryonic cortex during the period of interneuron dispersion (Fig. 4A,C) (Tiveron et al., 2006; Stumm et al., 2007). In turn, migrating cortical interneurons express the Cxcl12 receptor Cxcr 4 (Fig. $4 B, D$ ) (Stumm et al., 2003, 2007). At early stages, Cxcr4positive cells were localized at the SVZ and $\mathrm{MZ}$ of the cortex, and very few cells were found in the CP (Fig. 4B). In contrast, many Cxcr4-positive cells were found to invade the $C P$ at later stages, starting from approximately E16.5 (Fig. 4D). These results suggest that interneurons may respond to cortical CXCL12 via the CXCR4 receptor during their intracortical migration.

\section{CXCL12 promotes the migration of MGE-derived interneurons}

We have recently shown that CXCL12, secreted from the meninges, enhances the dispersion of Cajal-Retzius cells along the surface of the embryonic cortex (Borrell and Marín, 2006). Similarly, CXCL12 has been shown to promote the migration of striatal neuronal precursors in vitro (Stumm et al., 2003). The highly specific expression of $\mathrm{Cxcl12}$ in the compartments used by interneurons for their intracortical dispersion suggests that these neurons may use a similar mechanism than Cajal-Retzius cells to disperse themselves by tangential migration along the cortex. To start testing this hypothesis, we cocultured E13.5 MGE explants with aggregates of COS cells expressing Cxcl12 in collagen or Matrigel matrices. In these experiments, CXCL12 elicits a potent chemotaxis over MGE-derived cells $(n=26)$ (Fig. $5 A, B, G)$. To determine whether the migration-promoting effect of CXCL12 on MGE-derived cells was mediated by its high-affinity receptor CXCR4, we next performed loss-of-function experiments. First, we applied AMD3100, a specific antagonist of CXCR4 (Donzella et al., 1998; Lazarini et al., 2000; Rubin et al., 2003), to the medium in coculture experiments. Analysis of these experiments revealed that treatment with the CXCR4 inhibitor completely abolished the motogenic effect produced by CXCL12 $(n=14)$ (Fig. 5C, $D, G$ ). Second, we performed similar coculture experiments confronting Cxcl12-expressing COS cells to MGE-derived cells from $\mathrm{Cxcr} 4$ mutant embryos. These experiments confirmed that CXCR4 function mediates the chemotaxis elicited by CXCL12 in migrating interneurons $(n=17)$ (Fig. $5 E, F, H)$.

\section{CXCR4 is required for the intracortical migration of interneurons}

Previous studies have shown that the tangential migration of cortical interneurons from the subpallium to the cortex is not affected in Cxcl12 or Cxcr4 mutant embryos (Stumm et al., 2003, 2007; Tiveron et al., 2006), suggesting that this phase of the migration of cortical interneurons does not depend on CXCL12/ 


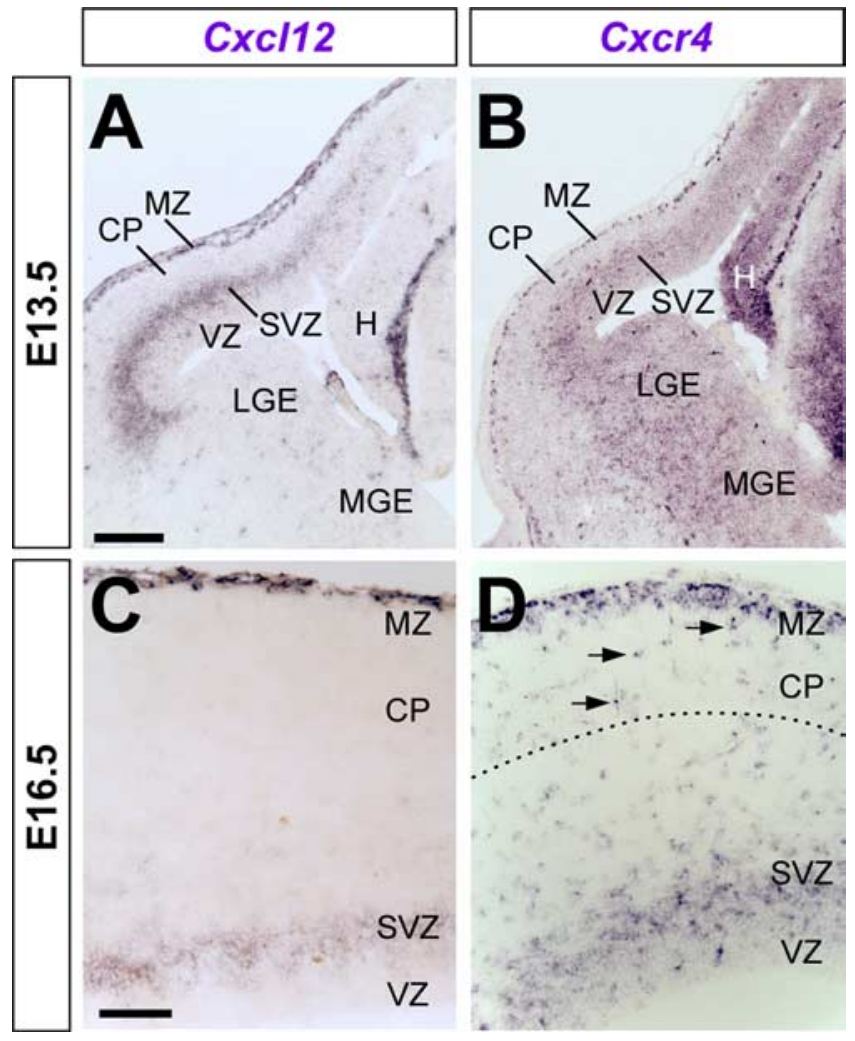

Figure 4. $\quad(x \mathrm{C} / 12$ and $C x \mathrm{Cr} 4$ expression in the developing mouse cortex. $A-D$, Coronal sections through the telencephalon of E13.5 $(\boldsymbol{A}, \boldsymbol{B})$ and E16.5 $(\boldsymbol{C}, \boldsymbol{D})$ embryos showing mRNA

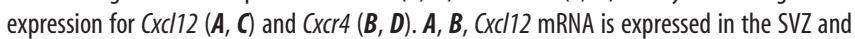
meninges overlying the $M Z$ of the cortex. CXcr4-expressing cells, putative cortical interneurons, migrate through the same cortical compartments. C, D, CX/12 mRNA expression is maintained in the SVZ and MZ of the cortex at E16.5. Expression in the SVZ has extended to medial cortical regions. CXcr4-expressing neurons are observed in the SVZ and MZ, but many positive cells are also observed inside the $(P$ at this stage ( $\boldsymbol{D}$, arrows). H, Hippocampus; LGE, lateral ganglionic eminence. Scale bars: $A, B, 200 \mu \mathrm{m} ; \boldsymbol{C}, \boldsymbol{D}, 100 \mu \mathrm{m}$.

CXCR4 signaling. In contrast, it has been reported that the distribution of cortical interneurons is perturbed in the embryonic cortex (Stumm et al., 2003, 2007; Tiveron et al., 2006). Consistent with this observation, blockage of CXCR4 signaling in the embryonic cortex by injecting AMD3100 into the lateral ventricle of mouse embryos at E12.5 (Fig. $6 \mathrm{~A}$ ) also perturbed the distribution of MGE-derived interneurons. As expected, $L h x 6$-expressing interneurons were mainly located in the $\mathrm{MZ}$ and SVZ of the cortex in vehicle-injected embryos $(n=3)$ (Fig. $6 B$; supplemental Fig. S2, available at www.jneurosci.org as supplemental material). In contrast, MGE-derived interneurons were no longer restricted to the MZ and SVZ in antagonist-injected embryos. Instead, interneurons were found throughout the entire thickness of the embryonic cortex, including the CP $(n=6)$ (Fig. $6 C)$. We next examined the distribution of Lhx6-expressing neurons in Cxcr4 mutant embryos. Loss of CXCR4 function also results in an abnormal distribution of MGE-derived interneurons in the developing cerebral cortex. Thus, in the absence of CXCR4 function, interneurons are less abundant in the cortical compartments that normally contain most interneurons at these stages, mainly the $\mathrm{MZ}$ and the SVZ, but they are more frequent in the developing $\mathrm{CP}$, which is normally devoid of interneurons at this period $(n=$ $4 ; 20.03 \pm 1.85,8.21 \pm 0.80$, and $20.76 \pm 2.39 \%$ interneurons in control E14.5 MZ, CP, and SVZ, respectively; $15.47 \pm 1.40$, $21.08 \pm 1.97$, and $13.70 \pm 2.21 \%$ interneurons in $\mathrm{Cxcr}^{-/-} \mathrm{E} 14.5$
$\mathrm{MZ}, \mathrm{CP}$, and SVZ, respectively; $p<0.05$ for $\mathrm{MZ}$ and $p<0.001$ for $\mathrm{CP}$ and SVZ, $\chi^{2}$ test) (Fig. $6 D, E, G, H$; supplemental Fig. S2, available at www.jneurosci.org as supplemental material). Thus, interneurons migrating through both the MZ and SVZ appear to be affected by the loss of CXCR4 function. This conclusion is further supported by the observation of many ectopic small Reln + cells (putative interneurons) in the CP of $\mathrm{CxCr}^{-/-}$embryos at E14.5 (Fig. 6I). At this stage, Reln-expressing interneurons are normally confined to the MZ, intermingled with the large, Relnexpressing Cajal-Retzius cells (Fig. 6F). Altogether, these experiments reinforce the notion that CXCL12/CXCR4 signaling is required for the distribution of GABAergic interneurons in the embryonic cortex.

\section{CXCR4 function prevents premature $\mathrm{CP}$ invasion by interneurons}

The previous results are consistent with the hypothesis that CXCL12/CXCR4 signaling promotes the tangential dispersion of interneurons through the MZ and SVZ and prevents them from invading the $\mathrm{CP}$ ahead of time. It is possible, however, that the observation of ectopic Lhx6-expressing cells in the CP in the absence of CXCR4 function (Tiveron et al., 2006; present study) only reflects that interneurons have an increased probability of migrating through the $\mathrm{CP}$, but not that they end their tangential dispersion by prematurely entering the $\mathrm{CP}$. To test this idea, we followed a single cohort of MGE-derived interneurons by labeling cells born at E12.5 with a BrdU pulse. In control embryos, analysis of the distribution of cells born at E12.5 in the E16.5 cortex demonstrated that E12.5 MGE-derived interneurons (Lhx6+ and BrdU+) are still primarily confined to the $\mathrm{MZ}$ and the SVZ at this stage (Fig. $\left.6 J, J^{\prime}, K\right)$. In contrast, in $C x c r 4^{-1-}$ embryos, E12.5 MGE-derived interneurons were preferentially located in the CP at E16.5 (Fig. $6 L, L^{\prime}, K$ ). Thus, in the absence of CXCR4 function, MGE-derived interneurons do not distribute evenly through the embryonic cortex but rather preferentially allocate themselves into the CP.

Analysis of the distribution of cortical Lhx6- and BrdU+ cells (which primarily, but not exclusively, correspond to pyramidal cells) born at E12.5 in E16.5 Cxcr4 ${ }^{-/-}$embryos uncovered two additional findings. First, the laminar location of projection neurons is not importantly affected by the absence of CXCR4 signaling at this stage (Fig. $6 \mathrm{M}$ ). This suggests that the abnormal location of MGE-derived interneurons is not an indirect consequence of the displacement of projection neurons. Second, and most remarkably, the abnormal location of E12.5 MGE-derived interneurons in the CP of E16.5 Cxcr4 $4^{-/-}$embryos perfectly matches the distribution of projection neurons born at the same time (Fig. $6 K$, compare black and red dashed lines). Thus, CXCL12/CXCR4 signaling appears to be required not only to promote the tangential dispersion of MGE-derived interneurons but also to prevent their premature entry in the developing $\mathrm{CP}$.

\section{CXCR4 functions cell-autonomously in intracortical interneuron migration}

Our results suggest that CXCR4 functions cell-autonomously in migrating interneurons as a receptor controlling intracortical tangential dispersion and CP invasion. However, although pyramidal neurons seem to be normally located in the embryonic cortex in the absence of CXCR4 function, it is possible that other defects could indirectly affect the distribution of interneurons in $\mathrm{Cxcr}^{-1-}$ embryos. For example, the distribution of CajalRetzius cells is affected in the absence of CXCL12/CXCR4 signaling (Borrell and Marín, 2006; Paredes et al., 2006), and this could 


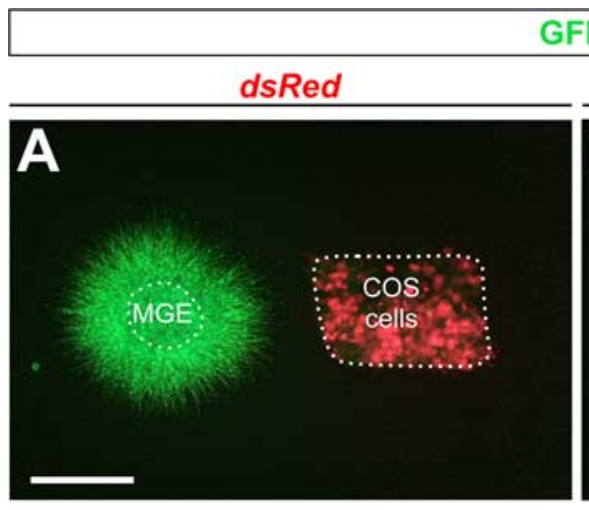

\section{GFP}
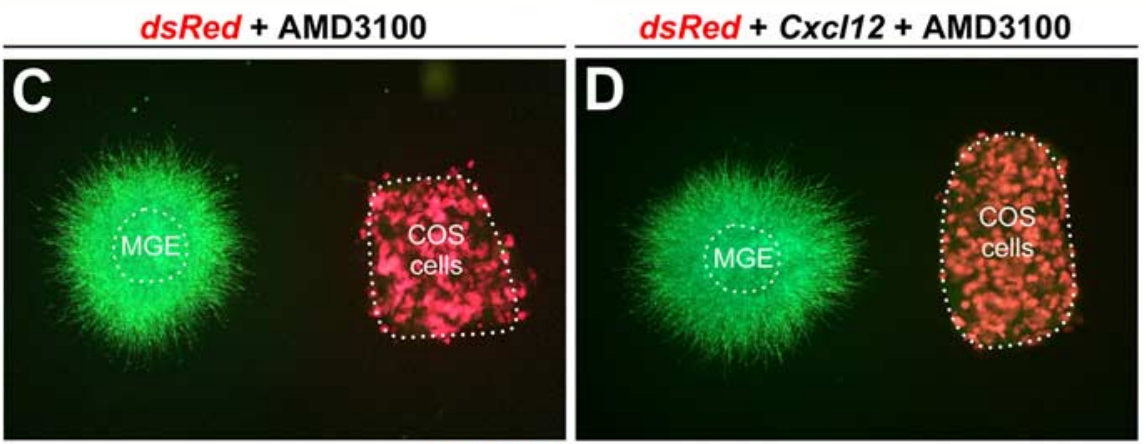

dsRed + Cxcl12
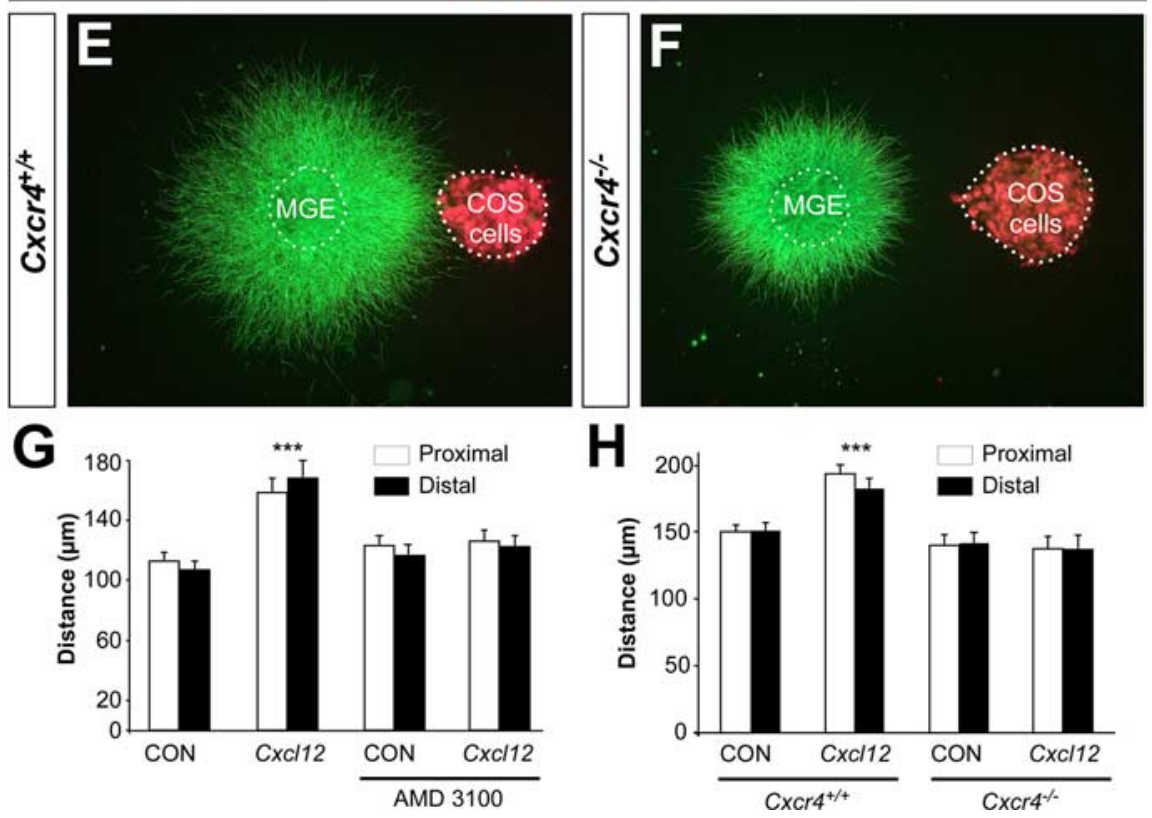

H

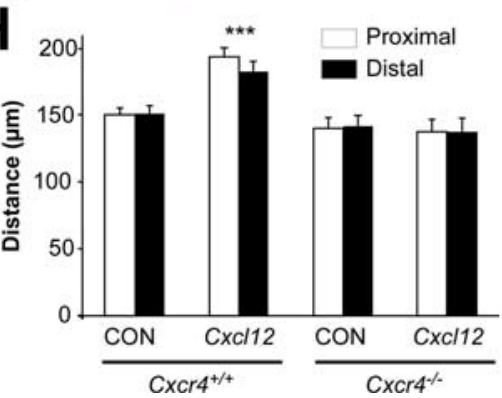

Figure 5. CXCL12 promotes the migration of MGE-derived cells. $A, B$, Migration of MGE-derived cells in response to mocktransfected $(\boldsymbol{A})$ or $\boldsymbol{X}$ Cl12-transfected $(\boldsymbol{B}) \operatorname{COS}$ cell aggregates cultured in collagen matrices for $36 \mathrm{~h}$. Dotted lines indicate the limits of the explants and $\operatorname{COS}$ cell aggregates. $\boldsymbol{C}, \boldsymbol{D}$, Migration of MGE-derived cells in response to mock-transfected $(\boldsymbol{C})$ or $(x \mathrm{C} / 12-$ transfected (D) COS cell aggregates cultured in collagen matrices in the presence of the CXCR4 inhibitor AMD3100.E, $F$, Migration of wild-type $(\boldsymbol{E})$ and $\mathrm{CxCr}^{-1-}(\boldsymbol{F})$ MGE-derived cells in response to $C x \mathrm{C} / 12$-transfected $\mathrm{COS}$ cell aggregates cultured in collagen matrices. G, Quantification of confrontation assays shown in $\boldsymbol{A}-\boldsymbol{D}$. CON, Control; D, distal quadrant; $P$, proximal quadrant. Histograms show average + SEM. $112.9 \pm 5.4($ CON, P); $107.0 \pm 5.8($ CON, D); $158.6 \pm 9.5($ CXCL12, P); $168.3 \pm 10.8$ (CXCL12, D); $123.4 \pm 5.8($ (CON+AMD3100, P); $117.0 \pm 6.9$ (CON+AMD3100, D); $126.0 \pm 7.3($ CXCL12+AMD3100, P); $122.0 \pm 7.5$ $\left(\right.$ CXCL12+AMD3100, D). ${ }^{* * *} p<0.001, t$ test. $\boldsymbol{H}$, Quantification of confrontation assays shown in $\boldsymbol{A}-\boldsymbol{D}$. Histograms show average + SEM. $150.0 \pm 5.0($ CON, P); $151.7 \pm 5.8($ CON, D); $193.5 \pm 7.0$ (CXCL12, P); $183.2 \pm 7.6$ (CXCL12, D); $140.5 \pm 8.4$ (CON CxCr4 $\left.{ }^{-/-}, \mathrm{P}\right) ; 142.4 \pm 8.3\left(\mathrm{CON}\right.$ CxCr4 $\left.{ }^{-/-}, \mathrm{D}\right) ; 138.0 \pm 9.2\left(\mathrm{CXCL}_{12} \mathrm{CXCr}^{-/-}, \mathrm{P}\right) ; 137.7 \pm 10.1$ (CXCL12 $\left.\mathrm{CXCr}^{-/-}, \mathrm{D}\right)$. ${ }^{* * *} p<0.001, t$ test. Scale bar, $300 \mu \mathrm{m}$.

indirectly affect the location of MGE-derived interneurons. To rule out this possibility, we transplanted portions of the MGE from E13.5 control and $\mathrm{Cxcr}^{-1-}$ embryos into the cortical VZ of host slices obtained from wild-type embryos at the same stage (Fig. 7A). To follow MGE-derived cells in this assay, we gave a BrdU pulse to the donor pregnant females $12 \mathrm{~h}$ before transplantation (Fig. 7A). After $48 \mathrm{~h}$ in culture, control MGE-derived interneurons were found mostly outside the $\mathrm{CP}$, whereas $\mathrm{CxCr}^{-/-}$interneurons were preferentially observed in the $\mathrm{CP}$ (Fig. $7 B-$ $D$ ). These results demonstrate that CXCR4 functions cell-autonomously in interneurons to control their migration through the embryonic cortex.

\section{Laminar position and tangential} dispersion of GABAergic interneurons requires CXCL12/CXCR4 signaling Our results suggest that CXCL12/CXCR4 signaling controls the intracortical tangential dispersion of GABAergic interneurons during embryonic development. As part of this function, CXCL12/CXCR4 signaling prevents interneurons from prematurely accumulating in the CP. Although modifications in the embryonic development of the cerebral cortex are frequently corrected during early postnatal stages, it is conceivable that the defects found in the embryonic cortex of $\mathrm{Cxcr}^{-/-}$mice may have an impact in the final distribution of interneurons in the mature cortex. Unfortunately, $\mathrm{CxCr}^{-1-}$ mice die perinatally because of hematopoietic and cardiac defects (Zou et al., 1998), preventing the analysis of the function of $\mathrm{Cxcr} 4$ in the final distribution of cortical interneurons. To overcome this problem, we used ultrasound-guided microtransplantation of the MGE to perform long-term in vivo fate-mapping analysis of transplanted cells (Olsson et al., 1997). In brief, we simultaneously transplanted E15.5 GFP-expressing MGE-derived cells and E15.5 $\mathrm{Cxcr4}^{-/-}$MGE-derived cells into the MGE of E15.5 wild-type embryos and analyzed the distribution of wild-type and mutant cells in the cortex of $\mathrm{P} 14$ transplanted mice. In all cases, donor pregnant females were BrdU injected $12 \mathrm{~h}$ before dissection of the MGE to ensure that the analysis was performed only on transplanted cells that divided last in the donor environment (Fig. 8A). Wild-type transplanted cells (GFP-expressing MGE-derived cells labeled with BrdU at E15.5, the internal control) were found primarily in upper layers of the P14 cortex, with a small fraction distributed through deeper layers $(n=$ 4; a total of 937 wild-type and 847 mutant cells counted) (Fig. 8B,C). In contrast, many $\mathrm{Cxcr}^{-/-}$MGE-derived interneurons were not found in upper layers of the cortex but instead were abnormally located in layer $\mathrm{V}$ (Fig. $8 \mathrm{~B}, \mathrm{C}$ ). Thus, in the absence of CXCR4 function, many GABAergic interneurons fated for upper 
layers of the cortex fail to reach their proper layer and instead allocate themselves to deep layers of the cortex, which are normally occupied by early-born interneurons.

The previous results suggest that premature invasion of the $\mathrm{CP}$ during embryonic development by $\mathrm{Cxcr}^{-/-}$MGE-derived interneurons modifies their normal laminar destination. Another prediction from our embryonic analysis is that the early accumulation of interneurons in the CP should impact their overall distribution throughout the entire cortex. To test this hypothesis, we analyzed the previous transplantation experiments by comparing the spatial distribution of wild-type and $\mathrm{Cxcr4}^{-/-}$interneurons in the rostrocaudal and ML axes of the cortex. Quantification of the global dispersion of MGE-derived interneurons revealed that, in each experiment, approximately one-third of the entire population of $\mathrm{Cxcr}^{-/-}$interneurons consistently dispersed less distance than their wild-type counterparts $(n=3$; a total of 1385 wild-type and 883 mutant cells counted) (Fig. $8 D-G$; supplemental Fig. S3, available at www.jneurosci.org as supplemental material). Of note, analysis of the migration of identified interneurons in telencephalic slices by time-lapse videomicroscopy did not reveal significant differences in the speed of migration between control and Cxcr4 ${ }^{-/-}$interneurons $(n=27$ neurons from three independent experiments; control neurons, $56.6 \pm 4.0 \mu \mathrm{m} / \mathrm{h} ; \mathrm{Cxcr}^{-/}$ neurons, $60.9 \pm 4.4 \mu \mathrm{m} / \mathrm{h} ; p=0473, t$ test; data not shown), which suggests that the defects observed in the regional distribution of interneurons are not attributable to a decrease in the overall speed of migration in mutant interneurons. In summary, loss of CXCR4 function affects not only the laminar allocation of interneurons but also reduces their capacity for tangential dispersion throughout the cortex.

\section{Discussion}

Our results demonstrate that CXCL12/ CXCR4 interactions mediate the intracortical tangential migration of GABAergic interneurons and that this signaling system is essential for their normal integration in the cerebral cortex. We found that GABAergic interneurons avoid the $\mathrm{CP}$ as they initially enter the cerebral cortex, and they sustain their tangential dispersion for a period of $\sim 48 \mathrm{~h}$ in the mouse. CXCL12 is a key regulator of this process, because it represents a potent chemotactic factor for MGE-derived interneurons and its expression is specifically enriched in the routes used by interneurons to disperse tangentially through the cortex. CXCL12 function is mediated by CXCR4, which is expressed by cortical interneurons
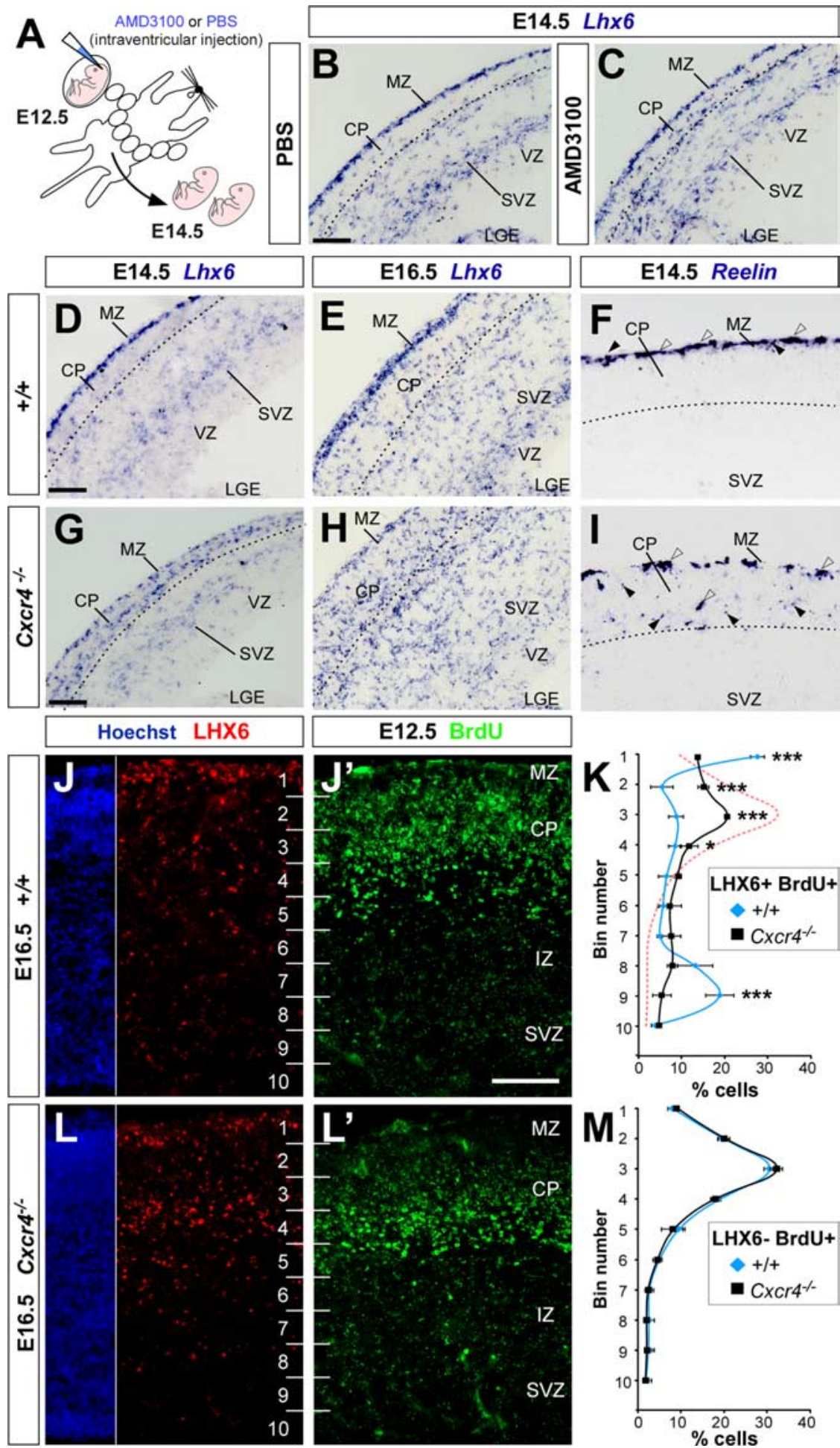

Figure 6. Loss of $\mathrm{CXcr} 4$ function leads to abnormal intracortical distribution of GABAergic interneurons during embryonic development. $A$, Schematic diagram of the experimental design. $B, C$, Coronal sections through the telencephalon of PBS-treated $(\boldsymbol{B})$ and AMD3100-treated (C) E14.5 embryos showing mRNA expression for Lhx6. D-I, Coronal sections through the telencephalon of wildtype $(\boldsymbol{D}-\boldsymbol{F})$ and $\mathrm{XXCr}^{-/-}(\mathbf{G}-\boldsymbol{I})$ E14.5 $(\boldsymbol{D}, \boldsymbol{F}, \boldsymbol{G}, \boldsymbol{I})$ and $16.5(\boldsymbol{E}, \boldsymbol{H})$ embryos showing mRNA expression for $L h \times 6(\boldsymbol{D}, \boldsymbol{E}, \boldsymbol{G}, \boldsymbol{H})$ and $R / n(\boldsymbol{F}$, I). Arrowheads point to putative GABAergic interneurons; open arrowheads point to Cajal-Retzius cells. $J^{\prime}, J^{\prime}, L, L^{\prime}$, Coronal sections through the somatosensory cortex of wild-type $\left(\boldsymbol{J}\right.$ and $\boldsymbol{J}^{\prime}$ are the same section) and $\mathrm{CxC}^{-4^{-/}}$( $\boldsymbol{L}$ and $\boldsymbol{L}^{\prime}$ are the same section) E16.5 embryos that had received a single BrdU injection at E12.5, showing immunohistochemistry for $L h \times 6(J, L)$ and $\operatorname{BrdU}\left(J^{\prime}, L^{\prime}\right)$. Numbers identify bins for quantification. DAPI ( $4^{\prime}, 6$-diamidino-2-phenylindole) staining in the same sections $(J, L)$ was used to define cortical layers. $\boldsymbol{K}$, Quantification of the distribution of E12.5 Lhx6+/BrdU + cells (putative MGE-derived interneurons) in wild-type and $\mathrm{CXCY}^{-1-}$ E16.5 embryos. Numbers in ordinatesidentify bins for quantification. ${ }^{*} p<0.05 ;{ }^{* * *} p<0.001 ; \chi^{2}$ test. The red dashed line indicates the distribution of E12.5 Lhx6 - /BrdU + cells, as in M. M, Quantification of the distribution of E12.5 Lhx6 - B BrdU + cells (putative projection neurons) in wild-type and $\mathrm{CXCr}^{-1-}$ E16.5 embryos. Numbers in ordinates identify bins for quantification. $p=$ $0.2, \chi^{2}$ test. Scale bars: $\boldsymbol{B}-\mathbf{E}, \mathbf{G}, \boldsymbol{H}, 100 \mu \mathrm{m} ; \boldsymbol{F}, \boldsymbol{I}, 50 \mu \mathrm{m} ; \boldsymbol{J}, \boldsymbol{J}^{\prime}, \boldsymbol{L}, \boldsymbol{I}^{\prime}, 300 \mu \mathrm{m}$. Error bars indicate SEM. LGE, Lateral ganglionic eminence. 

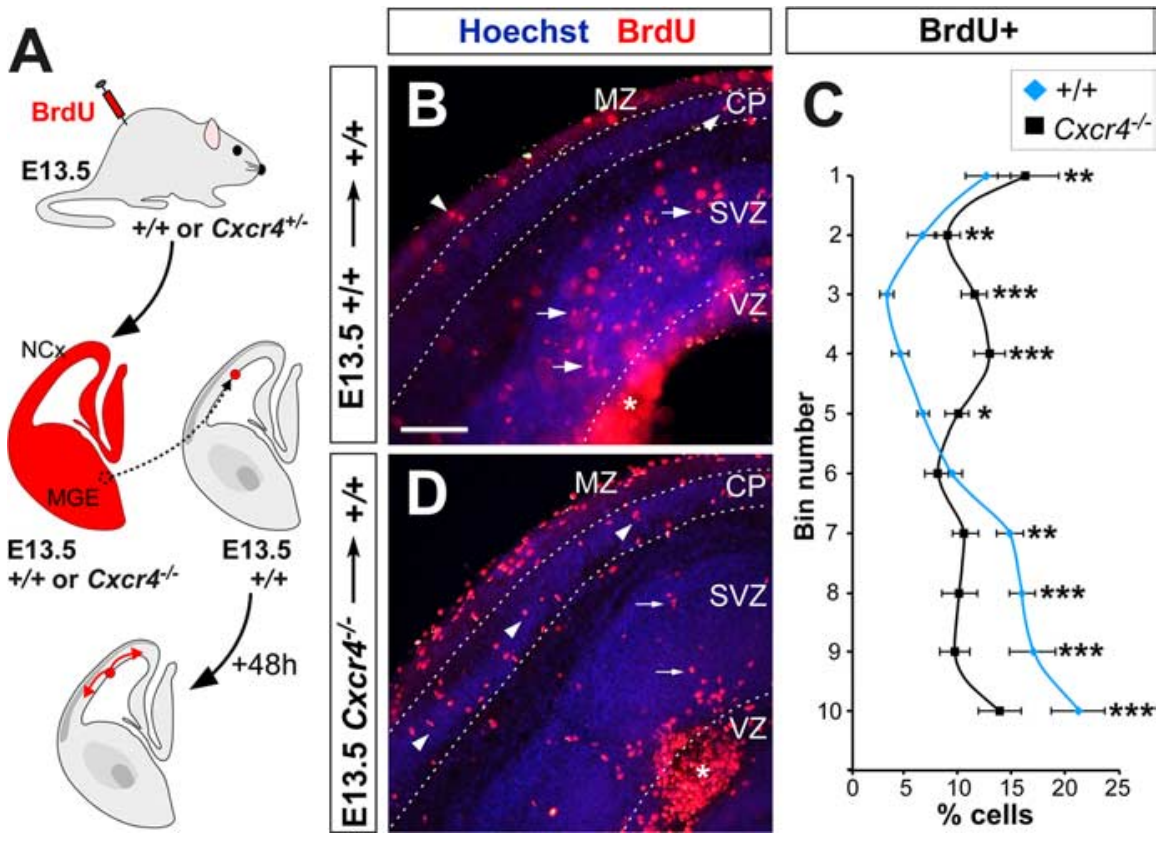

Figure 7. CXCR4 functions cell-autonomously to control the intracortical dispersion of MGE-derived cells. $\boldsymbol{A}$, Schematic diagram of the experimental design. NCx, Neocortex. $\boldsymbol{B}, \boldsymbol{D}$, Immunohistochemistry against BrdU in microtransplantation slice assays in which E13.5 wild-type $(\boldsymbol{B})$ or $C x C r 4^{-/-}$(D) MGE explants obtained from acutely BrdU-injected females were transplanted to the VZ of E13.5 wild-type slices and cultured for $48 \mathrm{~h}$. Scale bar, $100 \mu \mathrm{m}$. C, Quantification of the distribution of E13.5 BrdU+ MGE-derived cells from wild-type and $C x\left(r 4^{-1-}\right.$ embryos. Numbers in ordinates identify bins for quantification. ${ }^{*} p<0.05$; ${ }^{* *} p<0.01 ;{ }^{* * *} p<0.001 ; \chi^{2}$ test. Error bars indicate SEM.

as they migrate through the cortex. Loss of CXCR4 function perturbs the intracortical migration of interneurons and results in their premature accumulation in the embryonic CP. In the long term, early invasion of the CP by GABAergic interneurons in the absence of the CXCR4 function results in modifications of the normal laminar and regional distribution of these neurons in the postnatal cortex.

\section{A waiting period for cortical GABAergic interneurons}

Our experiments demonstrate that cortical GABAergic interneurons are not directed toward the $\mathrm{CP}$ as they first enter the cortex. Instead, GABAergic interneurons born at a specific stage during development remain within the $\mathrm{MZ}$ and the SVZ for a period of $\sim 48$ h before they start invading the CP. Our results suggest that this behavior is not attributable to the existence of nonpermissive or chemorepellent factors for interneurons in the CP but, rather, because the migratory pathways used by interneurons to disperse tangentially through the cortex contain a much more permissive/ chemoattractive activity than the CP.

The observation that GABAergic interneurons, after having reached the cortex, remain in the $\mathrm{MZ}$ and $\mathrm{SVZ}$ for a relatively long period of time before entering the $\mathrm{CP}$ is highly reminiscent of the behavior of thalamocortical axons during development. Thalamic projections arrive to the cortex before their target layer 4 neurons have migrated into the $\mathrm{CP}$, so they accumulate and wait in the zone immediately below the CP, the subplate, until its target layer is ready to accept afferent projections (Shatz and Luskin, 1986; Ghosh et al., 1990; Molnár and Blakemore, 1995; López-Bendito and Molnár, 2003). Similarly, each cohort of newborn interneurons appears to wait in the cortex for a period of time before entering the developing CP. Our heterochronic transplantation experiments, in which interneurons born at E13.5 can start invading the CP at E15.5, whereas interneurons born at this stage require older tissue (E17.5) to migrate into the $\mathrm{CP}$, suggest that this is the case. Thus, similar to the notion that thalamic axons wait for their layer 4 targets, each cohort of interneurons appears to wait that their synchronically generated projection neurons reach the appropriate position in the cortex before entering the CP.

\section{CXCL12/CXCR4 signaling controls} interneuron intracortical migration

Previous studies have shown that loss of CXCL12 or CXCR4 function does not prevent interneuron migration from the subpallium to the cortex (Stumm et al., 2003). However, the intracortical tangential dispersion of GABAergic interneurons does indeed depend on CXCL12/CXCR4 signaling. Perturbing CXCR4 function causes interneurons to lose their ability to respond to CXCL12 expressed by cells in the $\mathrm{MZ}$ and SVZ, thereby failing to recognize their primary routes of migration within the cortex (Tiveron et al., 2006; present study). Importantly, this defect is not indirectly caused by an alteration in the organization of the developing cortex in $\mathrm{Cxcr} 4^{-/-}$but, rather, by a direct effect on migrating interneurons. This is supported by two important findings: (1) CXCL12 strongly promotes the migration of MGE-derived interneurons via the CXCR4 receptor; and (2) the laminar position of projection neurons is normal in the developing cortex of $\mathrm{Cxcr} 4^{-1-}$ mice (i.e., projection neurons are able to migrate to their final position, whereas interneurons fail to retain their normal routes of migration within the embryonic Cxcr4 $4^{-/-}$cortex).

In addition to GABAergic interneurons, Cajal-Retzius cells derived from the cortical hem also rely on CXCL12 produced by the meninges to migrate through and retain their position in $\mathrm{MZ}$ (Borrell and Marín, 2006; Paredes et al., 2006). Thus, CajalRetzius cells and many GABAergic interneurons depend on the same guidance system to migrate close to the surface of the cortex, despite moving in opposite directions. This suggests that CXCL12/CXCR4 signaling does not directly control the direction of migration but, rather, defines the zone through which CajalRetzius cells and GABAergic interneurons should move. In summary, the generation of migration-promoting corridors appears to be a general mechanism promoting the tangential dispersion of neurons in the developing cortex.

Our analysis also reveals that the $\mathrm{CP}$ contains a chemoattractive activity for GABAergic interneurons. Thus, interneurons do not distribute randomly throughout the developing cortex in the absence of Cxcr4 function, as would have been expected if the only guidance information present in the cortex for these neurons would had been restricted to the routes of tangential dispersion (i.e., MZ and SVZ). Instead, CXcr4 $4^{-/-}$interneurons accumulate in the $\mathrm{CP}$, suggesting that this zone holds a chemoattractive activity for tangentially migrating interneurons that is only evident in the absence of CXCL12/CXCR4. This observation reveals a hierarchical organization of guidance cues for GABAergic interneurons in the developing cortex, with CXCL12 signaling dominating while interneurons disperse tangentially 
and an unknown factor present in the $\mathrm{CP}$ that only becomes perceptible by GABAergic interneurons after they have stopped responding to CXCL12. The molecular nature of this chemoattractive activity remains to be elucidated.

How do interneurons stop responding to CXCL12 signaling to enter the CP? The analysis of the expression pattern of Cxcr4 and Cxcl12 in the developing cortex suggests that interneurons do not simply stop using this signaling system by regulating the expression of these genes. Cxcl12 is expressed in the MZ and SVZ until late embryonic stages, and CXCR4-expressing cells appear to be able to invade the $\mathrm{CP}$ (Stumm et al., 2007). Although it is unknown whether CXCR4 receptors are present in the membrane of GABAergic interneurons as they enter the $\mathrm{CP}$, it is possible that other mechanisms may interfere in the CXCL12/CXCR4 signaling to regulate the progression of interneurons toward the CP. In the cerebellum, for example, ephrin-B reverse signaling can block CXCR4 function by activating the function of a regulator of heterotrimeric G-proteins. Thus, activation of ephrin-B function in granule cells blocks CXCR4 signaling, which allows these cells to migrate away from a source of CXCL12 (Lu et al., 2001). It remains to be explored whether similar molecular interactions could modulate cortical interneuron migration.

\section{Interneuron $\mathrm{CP}$ invasion is a key process in cortical development}

The present results suggest that the existence of a waiting period for GABAergic interneurons in the developing cortex is critical for their synchronization with the appropriate cohorts of projection neurons. This observation is supported by the longterm in utero transplantation experiments, which demonstrate that when interneurons prematurely invade the $\mathrm{CP}$ (as is the case for $\mathrm{Cxcr}^{-/-}$interneurons), many of them end up occupying an abnormal laminar position in the postnatal cortex. Specifically, many $\mathrm{Cxcr}^{-1-}$ interneurons born at E15.5 fail to reach the upper layers of the cortex, the final position for most interneurons born at this stage (Valcanis and Tan, 2003; Pla et al., 2006), and instead they end up residing in lower layers of the cortex, where earlyborn interneurons are normally located. Of note, not every $\mathrm{CxCr}^{-1-}$ interneuron fails to reach its appropriate layer in the cortex; indeed, a large proportion of $\mathrm{CxCr}^{-1-}$ interneurons manage to adopt a normal laminar location in these experiments. This implies that additional cues, either on the routes of migration or expressed by pyramidal cells, control the final laminar allocation of GABAergic interneurons. Furthermore, the existence of an inverse correlation between time of origin and lami-

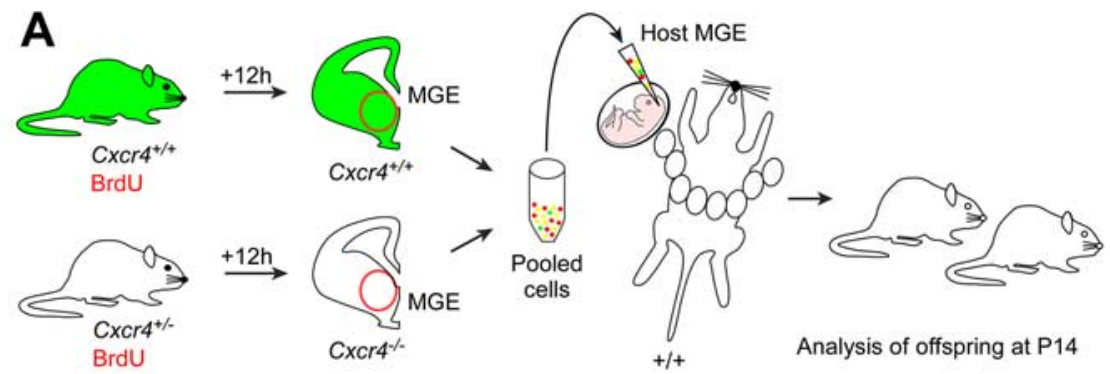

\begin{tabular}{|c|c|c|c|}
\hline Donors: E15.5 Cxcr4 ${ }^{+/+}(\mathrm{BrdU}+\mathrm{GFP})$ and E15.5 Cxcr4 ${ }^{-/}$(BrdU) & $\rightarrow$ Host: E15.5 \\
\hline Hoechst BrdU & GFP BrdU \\
\hline
\end{tabular}
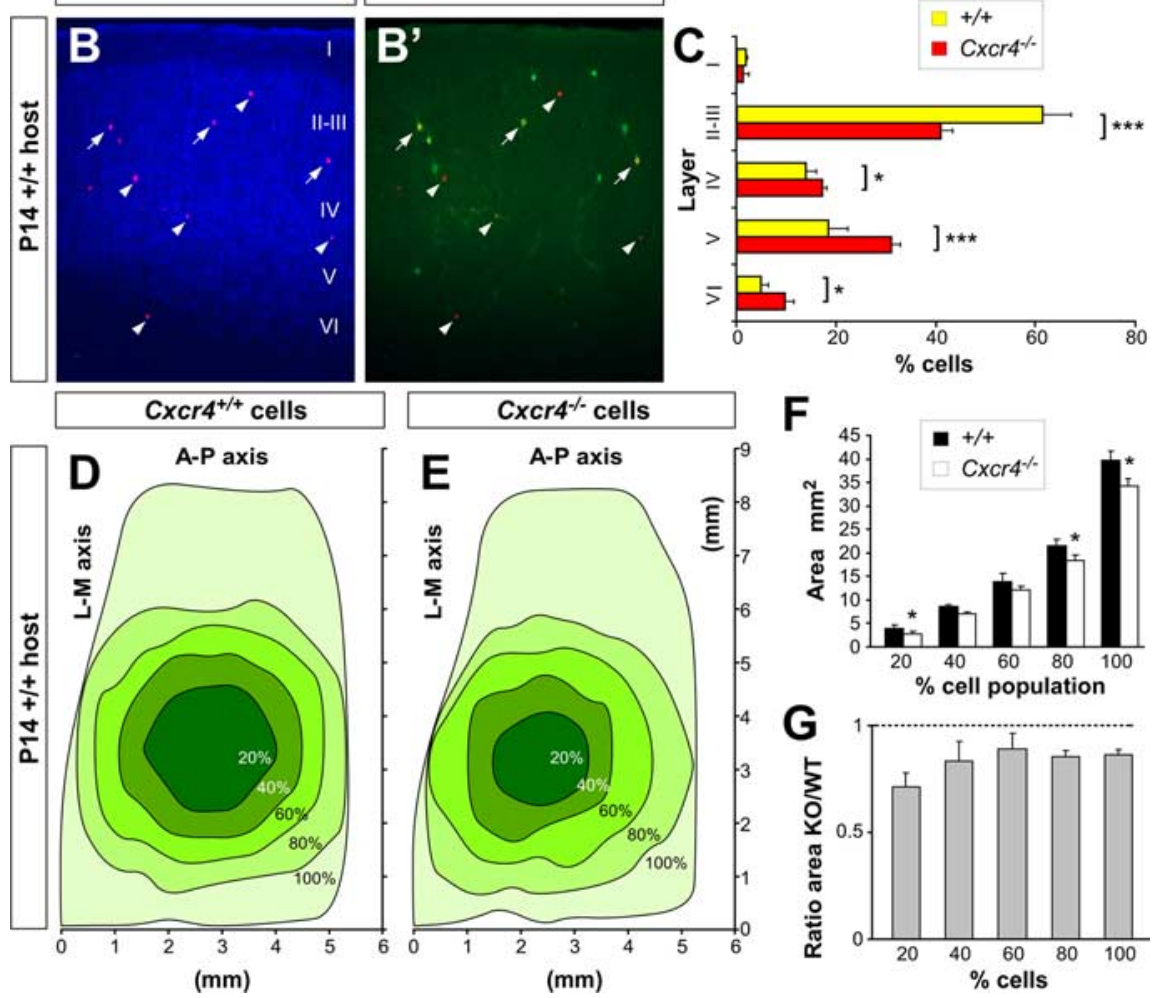

Figure 8. CXCR4 function is required for the laminar and regional distribution of cortical interneurons. $A$, Schematic diagram of the experimental design. GFP + and $\mathrm{Cxcr}^{+/-}$donor pregnant mice received a single injection of BrdU at E15. Twelve hours after BrdU injection, the MGE of $C x c r 4^{-1-}$ embryos was collected, dissociated, and pooled together with cells obtained from the MGE of GFP + embryos. Pooled donor MGE cells were then injected into the MGE of E15.5 wild-type host embryos. Host embryos were allowed to be born and analyzed at P14. $\boldsymbol{B}, \boldsymbol{B}^{\prime}$, Coronal section through the somatosensory cortex of a transplanted P14 mouse showing the distribution of E15.5 wild-type (BrdU+/GFP+) and E15.5 $\mathrm{Cxcr}^{-/-}$(BrdU+/GFP-) MGE-derived interneurons after nuclear staining [DAPI (4',6-diamidino-2-phenylindole)] and immunohistochemistry for BrdU (red) and GFP (green). Arrows point to wild-type (BrdU +/GFP+) cells; arrowheads indicate a $\mathrm{CxC4}{ }^{-/-}$(BrdU +/GFP-) cells. C, Quantification of the distribution of E15.5 wild-type (yellow) and $C x \mathrm{Cr}^{-/-}$(red) interneurons in the P14 cortex. ${ }^{*} p<0.05$; ${ }^{* * *} p<0.001$; $\chi^{2}$ test. $\boldsymbol{D}, \boldsymbol{E}$, Density maps showing the distribution of wild-type $(\boldsymbol{D})$ and $\left(\mathrm{x} C \mathrm{r}^{-/-}(\boldsymbol{E})\right.$ interneurons in the P14 cortex. Each green-coded area contains an increasingly higher proportion of the entire population of transplanted neurons, from $20 \%$ (darkest green area) to $100 \%$ (lightest green area). L-M, Lateral-medial; A-P, anteroposterior. $\boldsymbol{F}$, Quantification of the cortical area occupied by transplanted wild-type (filled bars) and $\mathrm{Cxcr}^{-1-}$ (open bars) interneurons in the P14 cortex. ${ }^{*} p<0.05$, Student's $t$ test. G, Quantification of the relative cortical area occupied by transplanted wild-type and $\mathrm{CCr}^{-/-}$interneurons in the P14 cortex. Error bars indicate SEM.

nar destination for some interneuron subtypes (Rymar and Sadikot, 2007) suggests that the mechanisms controlling the final laminar distribution of GABAergic interneurons are complex and heterogeneous.

Our analysis further reveals that premature invasion of the $\mathrm{CP}$ by $\mathrm{Cxcr} 4^{-/-}$interneurons also prevents their normal dispersion throughout the cortex. In these experiments, more than onethird of the population of $\mathrm{Cxcr} 4^{-/-}$transplanted neurons disperses roughly half as far than wild-type interneurons, suggesting 
the CXCL12/CXCR4 signaling is required for this process in a large proportion of cortical GABAergic interneurons. Thus, the waiting period preceding the invasion of the $\mathrm{CP}$ also serves to give GABAergic interneurons the time required to disperse tangentially and colonize those regions of the cortex that are located furthest away from their origin in the subpallium. Because the ganglionic eminences occupy a much more smaller area than the overlying cortical sheet, it does seem logical that a mechanism is in place to ensure that GABAergic interneurons have enough time to disperse throughout the entire cortex before ending their migration. Such a mechanism (preventing premature CP invasion) also helps to explain why interneurons do not concentrate in regions of the cortex that are closer to the subpallium and instead continue migrating until they populate all cortical areas.

\section{References}

Anderson SA, Eisenstat DD, Shi L, Rubenstein JL (1997) Interneuron migration from basal forebrain to neocortex: dependence on Dlx genes. Science 278:474-476.

Ang Jr ES, Haydar TF, Gluncic V, Rakic P (2003) Four-dimensional migratory coordinates of GABAergic interneurons in the developing mouse cortex. J Neurosci 23:5805-5815.

Borrell V, Marín O (2006) Meninges control tangential migration of hemderived Cajal-Retzius cells via CXCL12/CXCR4 signaling. Nat Neurosci 9:1284-1293.

Butt SJ, Fuccillo M, Nery S, Noctor S, Kriegstein A, Corbin JG, Fishell G (2005) The temporal and spatial origins of cortical interneurons predict their physiological subtype. Neuron 48:591-604.

Corbin JG, Nery S, Fishell G (2001) Telencephalic cells take a tangent: non-radial migration in the mammalian forebrain. Nat Neurosci 4:1177-1182.

D’Arcangelo G, Miao GG, Chen SC, Soares HD, Morgan JI, Curran T (1995) A protein related to extracellular matrix proteins deleted in the mouse mutant reeler. Nature 374:719-723.

Donzella GA, Schols D, Lin SW, Este JA, Nagashima KA, Maddon PJ, Allaway GP, Sakmar TP, Henson G, De Clercq E, Moore JP (1998) AMD3100, a small molecule inhibitor of HIV-1 entry via the CXCR4 co-receptor. Nat Med 4:72-77.

Fairén A, Cobas A, Fonseca M (1986) Times of generation of glutamic acid decarboxylase immunoreactive neurons in mouse somatosensory cortex. J Comp Neurol 251:67-83.

Flames N, Long JE, Garratt AN, Fischer TM, Gassmann M, Birchmeier C, Lai C, Rubenstein JL, Marín O (2004) Short- and long-range attraction of cortical GABAergic interneurons by neuregulin-1. Neuron 44:251-261.

Ghosh A, Antonini A, McConnell SK, Shatz CJ (1990) Requirement for subplate neurons in the formation of thalamocortical connections. Nature 347:179-181.

Grigoriou M, Tucker AS, Sharpe PT, Pachnis V (1998) Expression and regulation of Lhx6 and Lhx7, a novel subfamily of LIM homeodomain encoding genes, suggests a role in mammalian head development. Development 125:2063-2074.

Hadjantonakis AK, Gertsenstein M, Ikawa M, Okabe M, Nagy A (1998) Generating green fluorescent mice by germline transmission of green fluorescent ES cells. Mech Dev 76:79-90.

Hensch TK (2005) Critical period plasticity in local cortical circuits. Nat Rev Neurosci 6:877-888.

Hevner RF, Daza RA, Englund C, Kohtz J, Fink A (2004) Postnatal shifts of interneuron position in the neocortex of normal and reeler mice: evidence for inward radial migration. Neuroscience 124:605-618.

Kriegstein AR, Noctor SC (2004) Patterns of neuronal migration in the embryonic cortex. Trends Neurosci 27:392-399.

Lavdas AA, Grigoriou M, Pachnis V, Parnavelas JG (1999) The medial ganglionic eminence gives rise to a population of early neurons in the developing cerebral cortex. J Neurosci 19:7881-7888.

Lazarini F, Casanova P, Tham TN, De Clercq E, Arenzana-Seisdedos F, Baleux F, Dubois-Dalcq M (2000) Differential signalling of the chemokine receptor CXCR4 by stromal cell-derived factor 1 and the HIV glycoprotein in rat neurons and astrocytes. Eur J Neurosci 12:117-125.
López-Bendito G, Molnár Z (2003) Thalamocortical development: how are we going to get there? Nat Rev Neurosci 4:276-289.

López-Bendito G, Sturgess K, Erdelyi F, Szabo G, Molnar Z, Paulsen O (2004) Preferential origin and layer destination of GAD65-GFP cortical interneurons. Cereb Cortex 14:1122-1133.

Lu Q, Sun EE, Klein RS, Flanagan JG (2001) Ephrin-B reverse signaling is mediated by a novel PDZ-RGS protein and selectively inhibits G proteincoupled chemoattraction. Cell 105:69-79.

Marín O, Rubenstein JL (2001) A long, remarkable journey: tangential migration in the telencephalon. Nat Rev Neurosci 2:780-790.

Marín O, Rubenstein JL (2003) Cell migration in the forebrain. Annu Rev Neurosci 26:441-483.

Marín O, Yaron A, Bagri A, Tessier-Lavigne M, Rubenstein JL (2001) Sorting of striatal and cortical interneurons regulated by semaphorin/neuropilin interactions. Science 293:872-875.

Marín O, Plump AS, Flames N, Sanchez-Camacho C, Tessier-Lavigne M, Rubenstein JL (2003) Directional guidance of interneuron migration to the cerebral cortex relies on subcortical Slit1/2-independent repulsion and cortical attraction. Development 130:1889-1901.

McBain CJ, Fisahn A (2001) Interneurons unbound. Nat Rev Neurosci 2:11-23.

Miller MW (1985) Cogeneration of retrogradely labeled corticocortical projection and GABA-immunoreactive local circuit neurons in cerebral cortex. Brain Res 355:187-192.

Métin C, Baudoin JP, Rakic S, Parnavelas JG (2006) Cell and molecular mechanisms involved in the migration of cortical interneurons. Eur J Neurosci 23:894-900.

Molnár Z, Blakemore C (1995) How do thalamic axons find their way to the cortex? Trends Neurosci 18:389-397.

Nadarajah B, Parnavelas JG (2002) Modes of neuronal migration in the developing cerebral cortex. Nat Rev Neurosci 3:423-432.

Nadarajah B, Alifragis P, Wong RO, Parnavelas JG (2002) Ventricledirected migration in the developing cerebral cortex. Nat Neurosci $5: 218-224$.

Nery S, Fishell G, Corbin JG (2002) The caudal ganglionic eminence is a source of distinct cortical and subcortical cell populations. Nat Neurosci 5:1279-1287.

Olsson M, Campbell K, Turnbull DH (1997) Specification of mouse telencephalic and mid-hindbrain progenitors following heterotopic ultrasound-guided embryonic transplantation. Neuron 19:761-772.

Paredes MF, Li G, Berger O, Baraban SC, Pleasure SJ (2006) Stromalderived factor-1 (CXCL12) regulates laminar position of Cajal-Retzius cells in normal and dysplastic brains. J Neurosci 26:9404-9412.

Pla R, Borrell V, Flames N, Marín O (2006) Layer acquisition by cortical GABAergic interneurons is independent of Reelin signaling. J Neurosci 26:6924-6934.

Polleux F, Whitford KL, Dijkhuizen PA, Vitalis T, Ghosh A (2002) Control of cortical interneuron migration by neurotrophins and PI3-kinase signaling. Development 129:3147-3160.

Powell EM, Mars WM, Levitt P (2001) Hepatocyte growth factor/scatter factor is a motogen for interneurons migrating from the ventral to dorsal telencephalon. Neuron 30:79-89.

Pozas E, Ibañez CF (2005) GDNF and GFRalphal promote differentiation and tangential migration of cortical GABAergic neurons. Neuron 45:701-713.

Rubin JB, Kung AL, Klein RS, Chan JA, Sun Y, Schmidt K, Kieran MW, Luster AD, Segal RA (2003) A small-molecule antagonist of CXCR4 inhibits intracranial growth of primary brain tumors. Proc Natl Acad Sci USA 100:13513-13518.

Rymar VV, Sadikot AF (2007) Laminar fate of cortical GABAergic interneurons is dependent on both birthdate and phenotype. J Comp Neurol 501:369-380.

Shatz CJ, Luskin MB (1986) The relationship between the geniculocortical afferents and their cortical target cells during development of the cat's primary visual cortex. J Neurosci 6:3655-3668.

Somogyi P, Klausberger T (2005) Defined types of cortical interneurone structure space and spike timing in the hippocampus. J Physiol (Lond) $562: 9-26$

Stumm R, Kolodziej A, Schulz S, Kohtz JD, Hollt V (2007) Patterns of SDFlalpha and SDF-1gamma mRNAs, migration pathways, and phenotypes of CXCR4-expressing neurons in the developing rat telencephalon. J Comp Neurol 502:382-399. 
Stumm RK, Zhou C, Ara T, Lazarini F, Dubois-Dalcq M, Nagasawa T, Hollt $\mathrm{V}$, Schulz S (2003) CXCR4 regulates interneuron migration in the developing neocortex. J Neurosci 23:5123-5130.

Tanaka D, Nakaya Y, Yanagawa Y, Obata K, Murakami F (2003) Multimodal tangential migration of neocortical GABAergic neurons independent of GPI-anchored proteins. Development 130:5803-5813.

Tanaka DH, Maekawa K, Yanagawa Y, Obata K, Murakami F (2006) Multidirectional and multizonal tangential migration of GABAergic interneurons in the developing cerebral cortex. Development 133:2167-2176.

Tiveron MC, Rossel M, Moepps B, Zhang YL, Seidenfaden R, Favor J, Konig N, Cremer H (2006) Molecular interaction between projection neuron precursors and invading interneurons via stromal-derived factor 1
(CXCL12)/CXCR4 signaling in the cortical subventricular zone/intermediate zone. J Neurosci 26:13273-13278.

Valcanis H, Tan SS (2003) Layer specification of transplanted interneurons in developing mouse neocortex. J Neurosci 23:5113-5122.

Wichterle H, Turnbull DH, Nery S, Fishell G, Alvarez-Buylla A (2001) In utero fate mapping reveals distinct migratory pathways and fates of neurons born in the mammalian basal forebrain. Development 128:3759-3771.

Wichterle H, Alvarez-Dolado M, Erskine L, Alvarez-Buylla A (2003) Permissive corridor and diffusible gradients direct medial ganglionic eminence cell migration to the neocortex. Proc Natl Acad Sci USA 100:727-732.

Zou YR, Kottmann AH, Kuroda M, Taniuchi I, Littman DR (1998) Function of the chemokine receptor CXCR4 in haematopoiesis and in cerebellar development. Nature 393:595-599. 